\title{
Gliomatosis Cerebri Case Report Hospital Militar Central De Bogotá Colombia and Literature Review
}

\author{
Harold Palmera Pineda ${ }^{*}$, Nathalia Giraldo², Lina María Jiménez Rozo², Luis Orlando Rojas ${ }^{3}$ \\ ${ }^{I}$ Resident Neurosurgery Military University of Nueva Granada-Central Military Hospital, Colombia \\ ${ }^{2}$ Medicine Student, Military University of Nueva Granada, Colombia \\ ${ }^{3}$ Neurosurgery Specialist Central Military Hospital, Colombia
}

\begin{abstract}
*Corresponding Author: Harold Palmera Pineda, Resident Neurosurgery Military University of Nueva Granada-Central Military Hospital, Colombia, Email: har9hol@gmail.com
\end{abstract}

\begin{abstract}
Gliomatosis Cerebri $(G C)$ is defined as a diffuse infiltration of a glial tumor generally astrocytic that involves at least 3 cerebral lobes bilaterally and usually the condition extends to the brainstem. Its incidence represents approximately $1 \%$ of all brain tumors and occurs more frequently in young adults. The diagnosis is established from clinical environment, imaging and histological confirmation. The therapeutic possibilities are limited and the survival close to 2 years showing a high mortality. We report the case of an 11-year-old male patient who was treated at the Central Military Hospital of Bogotá, Colombia where the diagnosis was made and treatment was instituted.
\end{abstract}

Keywords: glial tumor, neuroimaging, histology, Central Military Hospital, cerebral gliomatosis.

\section{INTRODUCTION}

The World Health Organization defines Gliomatosis Cerebri (GC) since 1979 as a diffuse glioma, frequently astrocytic [1], with an extensive infiltrative pattern involving a significant part of the central nervous system (CNS), that preserves the surrounding architecture [2], but involves at least three cerebral lobes, shows a frequent bilateral growth and extension towards the brainstem, cerebellum and even the spinal cord [3]. Although it can be seen as a minor lesion from a radiological stand point, GC in its classic form (type 1), which is defined by the absence of a focal lesion, corresponds to a Grade 3 tumor in the WHO classification; and with the existence of a focal lesion (type 2), it becomes a grade 4 tumor in the WHO classification [4]. GC can be divided into two separate entities: type 1 is defined as the classic infiltrative diffuse lesion with the absence of a recognizable focal injury; meanwhile type $2 \mathrm{GC}$, which stems from type 1 , is characterized by an infiltrative diffuse lesion associated to a defined tumoral injury that, in imaging, shows the characteristics of high grade glial injuries [5-6].
GC makes up for approximately $1 \%$ of all primary brain tumors, and it can affect any age group [7], though its most frequently associated to people of forty years of age, and it has an average survival of 14,5 months. There is not a significant differentiation between genders, however, some literature suggests a slight prevalence in male patients. While GC cases of pediatric age are uncommon and there aren't extensive case series available, the largest reported population in a study consisted of 13 under-age patients, and it showed that the survival rate by 2 years is $67 \%$ and the average global survival is 27 months [8].

The clinical manifestations of GC are unspecified due to the broad distribution of the primary injuries [9], often misdiagnosed as different neurological diseases such as inflammatory diseases of the CNS, vasculopathies, or leukoencephalopathies [10]. And even though neuroimaging can show characteristic alterations, a definitive diagnosis requires histological confirmation [11].

Some of the most common manifestations are seizures, cognitive alterations, focal neurological deficits, endocranial hypertension and headache. The suspected diagnosis starts 
from the findings in the nuclear magnetic resonance (NMR) of the CNS that present: diffusive involvement of at least three cerebral lobes, with iso- to T1-hypointensity and $\mathrm{T} 2$ or FLAIR hypertensity, with the administration of contrast the difference is minimal to none (10). The definitive diagnosis is made through histology obtained through biopsy that shows neoplastic glial proliferation (of different types and grades) infiltrative and diffuse, with the preservation of structures [12].

\section{Clinical Case}

The patient is an 11-year-old male was admitted with a clinical picture of exotropia of the right eye related to diplopia and occasional headache that had been consistently evolving for five days. There wasn't relevant information on his medical history. Through physical examination it was found that he had third cranial nerve palsy on the right eye and papilledema on the back of the eye. Paraclinical testing takes place upon admission including blood chemistry and coagulation times, they did not present any alterations. A regular CAT scan of the brain reveals hypo dense right frontal lesion (Figure 1) suggesting a vasogenic edema, for that reason the decision was made to take magnetic resonance imaging (Figure 2) showing hyperdense areas in the frontal, parietal and right temporal regions, as well as the brainstem and the left cerebellar hemisphere; resonance of the neuroaxis was also performed and it showed no alterations; finally, spectroscopy (Figure 3) showed high lipid peaks in the frontal lobe voxel. With all the above, the proposed diagnostic impression was GC and a biopsy through stereotaxy on the frontal lobe is performed successfully with a pathology result that reported Anaplastic Astrocytoma defined by WHO as grade III with ki67 15\%, with that the diagnosis is established to be GC type 1 .

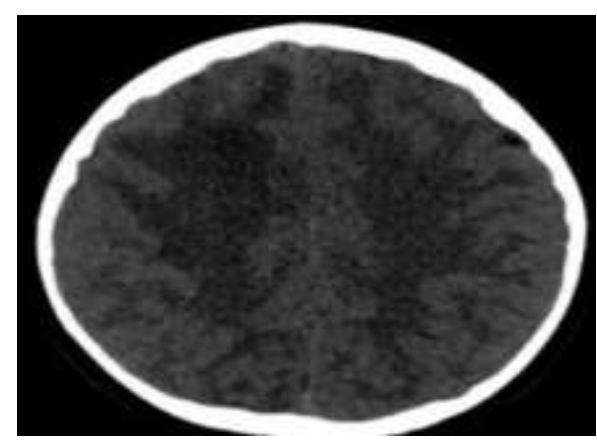

Figure 1

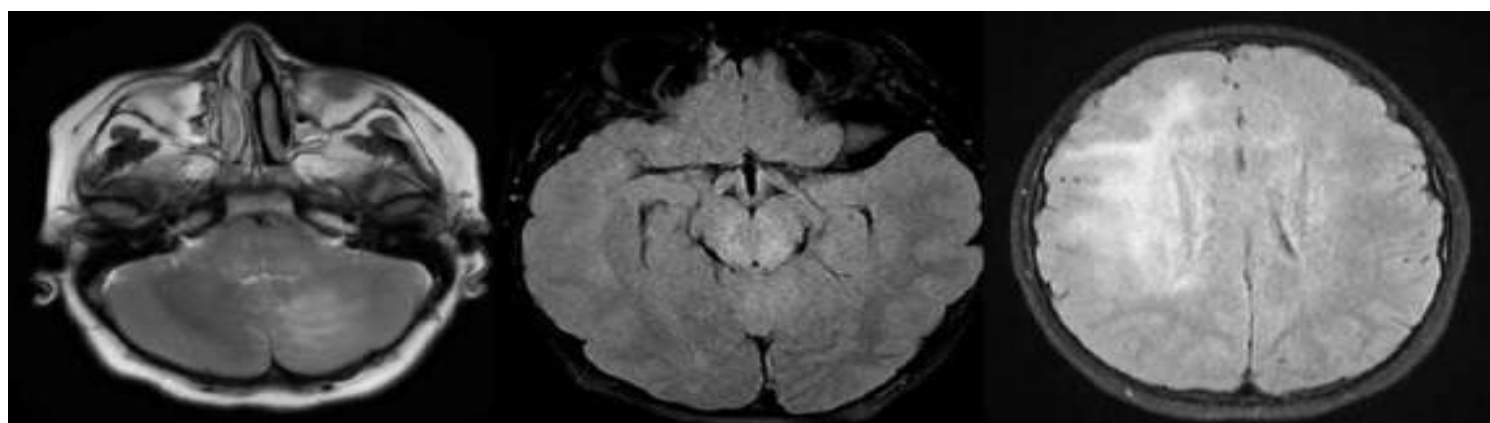

Figure 2

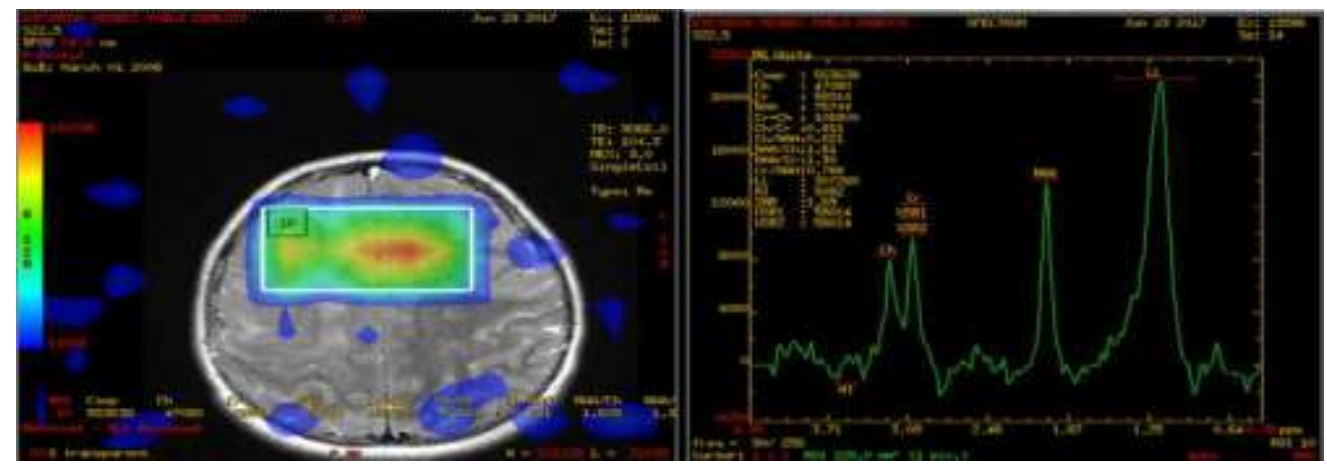

Figure 3 


\section{DISCUSSION}

Gliomatosis Cerebri is an uncommon entity that shows a high mortality rate in population of pediatric age. Since it does not have a typical clinical presentation its diagnosis tends to be attained through imaging and confirmed by histopathology. In this case, even though the third cranial nerve palsy was the first sign, a diffusive compromise of diverse other areas was witnessed and it could have had many different manifestations. Although it's a rare diagnosis, GC needs a premature suspicion and diagnosis because of the discrete but significant difference between the vital and functional prognosis of patients when they receive treatment early on. In the case of our patient the pathology was suspected and then followed up by testing that confirmed it, then an opportune multidisciplinary approach was established.

\section{REFERENCES}

[1] Louis DN, Perry A, Reifenberger G, Deimling A Von, Figarella D, Webster B, et al. The 2016 World Health Organization Classification of Tumors of the Central Nervous System: a summary. ActaNeuropathol [Internet]. 2016; 131(6):803-20. Available from: "http://dx.doi.org/10.1007/s00401-016-1545-1

[2] 2. Maharaj MM, Phan K, Xu J, Fairhall J, Reddy R, Rao PJ V. Gliomatosiscerebri : Prognosis based on current molecular markers. J ClinNeurosci [Internet]. 2017; 43:1-5. Available from: http://dx.doi.org/ 10.1016/j.jocn.2017.04.043

[3] Ruda R, Bertero L, Sanson M. GliomatosisCerebri : A Review. 2014;
[4] Quick-weller AJ, Tritt S, Kashefiolasl S. Positive influence of partial resection on overall survival of patients with overlapping glioblastomas. ClinNeurolNeurosurg [Internet]. 2017; Available from: http://dx.doi.org/ 10.1016/ j.clineuro.2017.06.021

[5] Coene B De, Cosnard G. Gliomatosiscerebri, imaging findings of 12 cases Gliomatosecérébrale, imagerie de 12 cas. 2010;

[6] Meligonis GE al. Gliomatosis of the Brain and Spinal. Surg Neurol. 57(6):399-404.

[7] González MG, Jato CL, Tuñas LMV, Pérez IF. Gliomatosis Cerebri :diagnóstico y tratamiento con temozolomida, a propósito de un caso. : $41-5$.

[8] Adachi H, Kitagawa M KT. Pediatric gliomatosiscerebri presenting with intratumoral hemorrhage leading to poor outcome. J cancer metastasis treat. 2016;(2):375-8.

[9] López MEN, Rosenfeld M, Dalmau J. Gliomatosis cerebral: estudio de 22 pacientes. Neurología [Internet]. 2010;25(3):168-73. Available from: http://dx.doi.org/ 10.1016/S0213-4853(10)70005-0

[10] Shimony N, Shofty B, Ram Z, Grossman R. Perioperative Risk Assessment of Patients with Gliomatosis Cerebri. World Neurosurg [Internet]. 2017;98:334-8. Available from: http://dx.doi.org/10.1016/j.wneu.2016.11.014

[11] Chen S, Yan ES, Buckner J, Lachance DH. Gliomatosiscerebri: clinical characteristics, management, and outcomes. 2014;112(2):26775.

[12] Cerebri G, Akimoto J. Clinicopathological Diagnosis of Gliomatosis Cerebri. 2006 ; (Table 1).

Citation: Harold Palmera Pineda, Nathalia Giraldo, Lina María Jiménez Rozo, Luis Orlando Rojas. Gliomatosis Cerebri Case Report Hospital Militar Central de Bogotá Colombia and literature review. ARC Journal of Clinical Case Reports. 2020; 6(1): 6-8. doi:dx.doi.org/ 10.20431/2455-9806.0601002.

Copyright: () 2020 Authors. This is an open-access article distributed under the terms of the Creative Commons Attribution License, which permits unrestricted use, distribution, and reproduction in any medium, provided the original author and source are credited. 